\title{
LA DOBLE RUPTURA DE 1973, CUARENTA AÑOS DESPUÉS. LA DEMOCRACIA SEMISOBERANA
}

\author{
Carlos Huneeus (corpcerc@rdc.cl) \\ Rodrigo Cuevas (rodrigocuevas@uchile.cl) \\ Instituto de Estudios Internacionales, Universidad de Chile
}

\begin{abstract}
El presente artículo analiza cómo enfrentaron los gobiernos democráticos de la Concertación de Partidos por la Democracia la doble ruptura producida por el golpe militar de 1973, la continuidad democrática de gobiernos elegidos en elecciones competitivas y el desmantelamiento del Estado de bienestar y el Estado empresario, por la transformación económica neoliberal, que creó nuevas bases del Estado y la sociedad. Se enfrentó la primera ruptura, aunque parcialmente, por el peso de los enclaves autoritarios, destacando la continuidad del ex dictador durante ocho años como comandante en jefe del Ejército. No se enfrentó la segunda, pues se optó por la continuidad del sistema económico, decisión de enorme importancia porque la estrategia de consolidación democrática giró en torno al crecimiento. Chile tiene crecimiento económico, pero se han debilitado severamente los partidos y la calidad de la democracia. Se concluye que se debe tener una evaluación matizada de la transición chilena y no es un modelo en América Latina, como se le ha considerado.
\end{abstract}

Palabras clave: Democratización, Chile, Calidad de la Democracia, partidos políticos, golpe de Estado.

\section{THE DOUBLE RUPTURE OF 1973, FORTY YEARS LATER. THE SEMI-SOVEREIGN DEMOCRACY}

This article examines how the democratic governments of the Coalition of Parties for Democracy faced the two ruptures caused by the 1973 military coup. These involved the democratic continuity of governments elected in competitive elections and the dismantling of the welfare and businessorientated state, to be replaced by a neoliberal economic transformation that created a new basis for state and society. The first was partially dealt with by the strength of authoritarian enclaves, particularly the fact that the former dictator continued as commander-in-chief of the Army for eight years. The second was not dealt with at all, because of a decision in favor of the continuity of the economic system, hugely important because democratic consolidation was rooted in economic growth. Chile achieved economic growth, although this severely weakened the parties and the quality of democracy. We can conclude that Chile's transition to democracy demands a balanced assessment, and, furthermore, that it is no model for Latin America as previously supposed.

Keywords: Democratization, Chile, Quality of Democracy, political parties, coup. 


\section{Introducción}

El artículo examina cómo fue enfrentada por los gobiernos democráticos de la Concertación de Partidos por la Democracia la doble ruptura producida por el golpe de Estado de 1973: la continuidad democrática representada por la alternancia de presidentes elegidos en elecciones competitivas y el sistema económico representado por el Estado de bienestar y el Estado empresario.

Chile es frecuentemente presentado como un caso emblemático en las nuevas democracias de la "tercera ola" (Huntington 1991) por haber tenido una exitosa transición desde el régimen militar del general Augusto Pinochet (1973-1990), logrando consolidar un sistema democrático de cierta calidad, con un destacado crecimiento económico y un sostenido avance en la disminución de la pobreza y en la mejoría de las condiciones de vida de millones de chilenos (Ffrench-Davis 2008; Muñoz 2007).

La democratización ha superado las enormes dificultades existentes en el cambio de régimen, que incluyó la continuidad del ex dictador por ocho años en la dirección del Ejército, logró hacer verdad y justicia por los atropellos a los derechos humanos, ${ }^{1}$ que incluyó la mayor cantidad de militares condenados por su responsabilidad en los atropellos a los derechos humanos dentro de los países de América Latina (A. Huneeus 2010) $)^{2}$. Se destacan especialmente los resultados económicos de la democracia, pues se redujo en forma considerable la pobreza, de un $45 \%$ de la población que vivía en ella en 1987 a sólo un 15,1\% el 2009. ${ }^{3}$ El crecimiento del PIB promedió un 5,0\% en los casi veinte años comprendidos entre 1990 y 2009, y el PIB por habitante se expandió a un promedio anual de 3,6\%, en comparación con 1,3\% durante el régimen militar. El mejoramiento de los salarios promedios reales ha sido impresionante: el 2009 eran 74\% superiores a los que hubo dos décadas antes y el salario mínimo se había multiplicado por 2,37. Esto es un claro contraste con los salarios durante la dictadura, pues en 1989 eran menores que los que había en 1970.

Los hitos en la verdad fueron la Comisión Rettig, establecida en 1990 por el presidente Patricio Aylwin, que investigó los casos que terminaron en muerte de personas y la Comisión Valech nombrada por el presidente Ricardo Lagos en 2004 para investigar los casos de tortura y que entregó el informe ese año.Véase Collins (2010).

2 Un minucioso resumen del desempeño económico y social de los gobiernos democráticos hace Angell (2009).Véase Muñoz (2007), Ffrench-Davis (2008) y los libros editados por Bascuñán et al. (2009).

3 Estos datos económicos son tomados de Ffrench-Davis (2013). 
Estos resultados contrastan con el estancamiento económico de la antigua democracia, pues entre 1950 y 1960 el PIB por habitante creció 1,18\%, por debajo del aumento de la población, levemente por encima de Argentina, 1,10\%, pero casi un tercio por debajo del crecimiento de Brasil y menos de la mitad del que tuvo México (Gerchunoff y Llach 1998). También fue bajo en los años siguientes, hasta la caída de la democracia en 1973. ${ }^{4}$ Los estudios de calidad de la democracia existentes sitúan a Chile en los primeros lugares de los índices que la miden y evalúan su desempeño económico-social. El índice de desarrollo humano 2012, preparado por el Programa de Naciones Unidas para el Desarrollo (PNUD), lo sitúa en el lugar 40 entre 187 países, mejorando la posición que tenía en el 2010, cuando estaba en el puesto 45 de los 160 países considerados, el mejor de América Latina. En 2012, la Fundación Bertelsmann lo ubica en el noveno lugar del "índice de transformación" entre los 128 países considerados en el estudio, superado por Uruguay, que se ubicaba en el quinto lugar, y en el noveno lugar en el management index, cayendo del segundo lugar que tenía en 2010. ${ }^{5}$ También el Banco Mundial destaca el desarrollo político y económico de Chile, ubicándolo en el primer lugar en el ranking de gobernanza entre los países latinoamericanos.

Un protagonista de la transición considera que fue la "más exitosa de Latinoamérica", por lo que la Concertación habría sido "la coalición más exitosa de la historia de Chile". ${ }^{7}$ Esta evaluación sería compartida por analistas extranjeros, que se refieren al “modelo chileno" (Ensignia y Nolte, 1991; Drake y Jaksic, 1995), el que entregaría lecciones a otros países de cómo avanzar de la dictadura a la democracia y salir del subdesarrollo.

Lograr simultáneamente el desarrollo económico y consolidar una democracia de calidad fue una aspiración de numerosas generaciones en la historia de Chile, sin haberlo conseguido. En la anterior democracia, que se rigió por la Constitución de 1925, se logró un desarrollo político que, junto con Uruguay, fue excepcional en América Latina, donde predominó la hegemonía militar (Rouquié 1984;2011), pero había alcanzado un bajo crecimiento económico. Mirando la evolución histórica del

4 Entre 1963 y 1973 el crecimiento de la economía chilena fue inferior al 2\%, muy por debajo de Argentina, Brasil y México, y del que tuvo la economía mundial, cercana al 3\% (Gerchunoff y Llach 1998).

5 Transformation Index, Berstelmann Stiftung, <http://www.bertelsmann-transformation-index. de/> (consulta: 20/5/2013).

6 Palabras de Enrique Correa, ex ministro secretario general de gobierno, entrevista en Qué Pasa, 4 de julio de 2008 .

7 Palabras de José Miguel Insulza, ex ministro del Interior del presidente Ricardo Lagos. "Si gana Piñera Chile no sufrirá grandes transformaciones”, entrevista La Tercera, 6 de enero de 2010. 
país, el economista Aníbal Pinto (1958) concluyó que había "gran contradicción entre el ritmo deficiente de la expansión de su economía y el desarrollo del sistema y la sociedad democrática", expresado en un "subcrecimiento en lo económico y el relativo sobreprogreso en lo político" (el enfasis es nuestro). Desde 1990, Chile habría roto ese frustrante pasado, porque estaría alcanzando simultáneamente un sostenido crecimiento económico y desarrollo político. El país estaría al borde de llegar a la tierra prometida, el desarrollo, buscado con muchos esfuerzos durante largos y difíciles años por distintos partidos y presidentes.

Los países con una dramática interrupción de su democracia, como Alemania, ${ }^{8}$ enfrentaron su restablecimiento aprendiendo de los errores cometidos en el pasado, construyendo un nuevo orden político en torno a valores comunes e instituciones compartidas, que le dieran mayor calidad. Además, establecieron un sistema económico y social que dio bienestar a la población y ayudó al desarrollo político y a la integración social. La ley fundamental alemana de 1949 terminó con el presidente fuerte, elegido por el voto popular de la república de Weimar (19181933), que ahora es elegido en forma indirecta, y el canciller federal recibió una fuerte autoridad, que sólo puede ser derribado por el voto de censura constructivo, es decir, cuando existe una mayoría para elegir al nuevo jefe de gobierno. La ley electoral ayudó a la concentración de los partidos, con un sistema proporcional que tiene la barrera legal del 5\%, para impedir su fragmentación. Se restableció y reforzó el Estado de bienestar, fundado a fines del siglo XIX, y se optó por una economía social de mercado, que integró los intereses de empresarios y trabajadores en igualdad de condiciones a través de la cogestión en las empresas, y con poderosas organizaciones empresariales y sindicales. El sistema económico goza de una alta legitimidad, que ha dado paz social y prosperidad a los alemanes, y es calificado de "centrista" porque se diferencia del social demócrata de los países escandinavos y del "modelo" capitalista de los EE.UU., Estos cambios institucionales hicieron posible el exitoso desarrollo político alemán y la estabilidad de sus gobiernos (Katzenstein 1987; Schmidt 2002).

Es a partir de lo anterior que nos preguntamos: ¿Qué instituciones tiene Chile hoy que demuestren que hemos sacado las lecciones de los errores cometidos? ¿Tiene ahora una democracia de mejor calidad? ¿Hay un orden económico-social que apoye el desarrollo político y dé estabilidad política e integración social?

$8 \quad$ Fue también el caso de España después de la muerte de Franco en 1975 (Huneeus, 1985). 


\section{Las limitaciones del desarrollo político}

La nueva democracia no se ha dado una nueva Constitución, pues rige la de 1980, que fue promulgada por el régimen autoritario siguiendo el modelo de "democracia protegida y autoritaria", considerada entonces como una alternativa a la democracia pluralista, manteniendo importantes recursos institucionales de ésta. La oposición a la Concertación se negó entonces a las reformas constitucionales que hubieran eliminado los enclaves autoritarios de ella (Garretón 1989; 1995). En la carta fundamental se estableció la tutela militar sobre las instituciones representativas, impuso un pluralismo limitado (art. $8^{\circ}$ ), tuvo una visión crítica de la soberanía popular, con senadores designados en alto número (nueve frente a 26 elegidos), dio una definición hostil hacia los partidos, que no los consideró como instituciones propias del orden político (art.19, Nr.15), tuvo una visión corporativista del derecho de asociación, proporcionó una definición neoliberal del sistema económico, que correspondía a quienes detentaban el poder entonces, e impuso un sistema de "supramayorías" muy por encima de las establecidas en las constituciones democráticas para asegurar la permanencia de sus principales recursos institucionales. Estos principios fueron ampliados en numerosas leyes orgánicas constitucionales, que, para ser reformadas, requieren de mayorías especiales. El sistema binominal fue un seguro adicional, que permite a la minoría obtener uno de los dos escaños en disputa con sólo el 33\% de los votos, imponiendo una tiranía de ésta más que limitar el poder de la mayoría.

Importantes instituciones de la "democracia protegida" se conservan en el texto constitucional vigente, a pesar de sus numerosas reformas, siendo las más importantes las de 1989 -que introdujo 54 cambios, incluyendo la eliminación del art. $8^{\circ}$ y moderó la tutela militar-y la de 2005 -eliminó los senadores designados y restableció la autoridad del presidente sobre los militares, pues éste puede destituir a un comandante en jefe mediante decreto fundado e informando previamente a la Cámara de Diputados y al Senado (art. 104, inc. 2).

Enseguida, su calidad es heterogénea, con instituciones que han alcanzando una considerable modernización, como el Poder Judicial, haciendo posible un mejor estado de derecho que entonces. Sin embargo, hay instituciones que son débiles, como los partidos, que tienen una severa debilidad institucional, e importantes desequilibrios entre los grupos de interés, pues por un lado los sindicatos alcanzan una limitada representación de los trabajadores, con un $12 \%$ de afiliación, en 
contraste con las poderosas organizaciones empresariales que les permite a éstas influir con mayor fuerza en la agenda pública.

Estas limitaciones incluyeron un dominio reservado en el policy making, mantenido fuera de las decisiones de las autoridades elegidas por el pueblo: el militar. Esto impuso una fuerte limitación a la autoridad presidencial y del congreso en un tema clave de la democratización, reforzado por la continuidad del general Pinochet como comandante en jefe del Ejército durante ocho años, después de los cuales podía entrar al Senado en su calidad de ex presidente, un caso único en las nuevas democracias en que el ex dictador permanece en la arena política.

Esto influyó en la cultura cívica de los chilenos, dominada por una evaluación crítica de las instituciones y las élites, un alto cinismo político, un apoyo mediocre a la democracia y una baja satisfacción con su desempeño, que contradice los buenos indicadores económicos. Hay una bajísima confianza hacia los políticos, en un contexto más amplio de baja confianza interpersonal y en las instituciones políticas.

\section{Gráfico 1}

La confianza interpersonal, 1988-2013

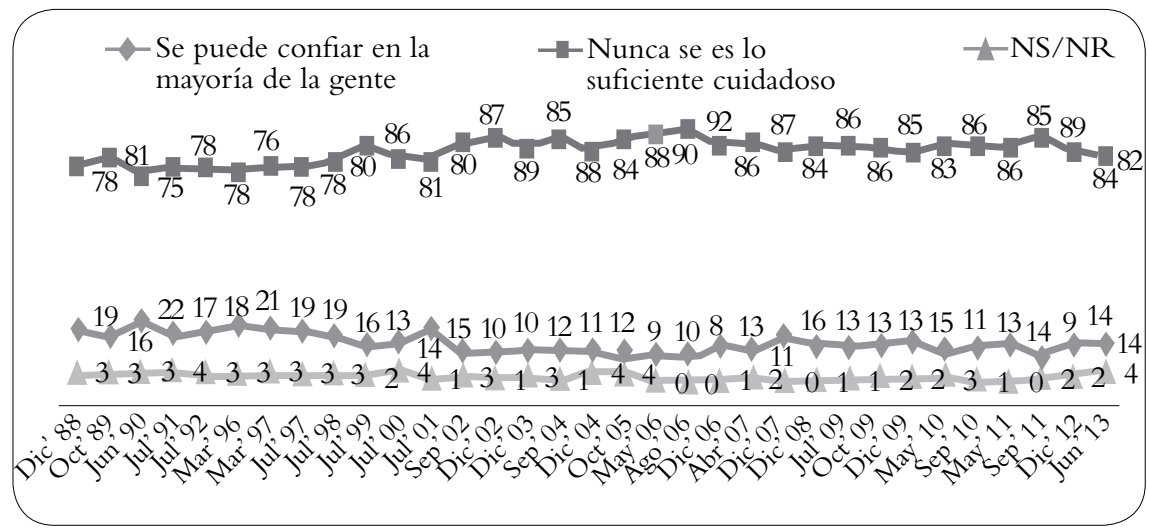

P: ¿Hablando en general, ¿cuánto cree Ud. que se puede confiar en las personas en Chile ahora? ¿Diría que se puede confiar en la mayoría de la gente o que uno nunca es lo suficientemente cuidadoso en el trato con los demás? Fuente: Barómetro de la Política, junio de 2013.

Este es un clarísimo retroceso en comparación al estado de los partidos en la anterior democracia, que fue admirada en el exterior. Ha habido una crisis de representación porque la juventud ha estado excluida de la ciudadanía política, al no inscribirse en los registros electorales desde la inauguración de la democracia. Si en 1989 el 89,9\% de la población en edad de ser ciudadana estaba inscrita, veinte años después era 
sólo el 68,02\%, habiendo una menor inscripción en los sectores populares. Sólo en 2009 se estableció la inscripción automática, sin enfrentar la crisis de representación, sino que agravándola, pues eliminó el voto obligatorio, que llevó al desplome de la participación política, que cayó al 40\% en las elecciones municipales del 2012, la más baja en comicios desde 1989.

Se ha producido el desplome organizativo, electoral y funcional de los partidos, que les impide cumplir sus importantes funciones en el sistema político, como es la agregación de intereses, apoyar al gobierno y al congreso. ${ }^{9}$ Sólo el 43\% de los encuestados en junio de 2013 nombra un partido por el cual votaría en las próximas elecciones, lo que constituye una caída respecto de los porcentajes de menciones que hubo antes, especialmente en los años 90, cuando no bajó del 67\% en las encuestas realizadas fuera de contextos electorales, que se empinó al $87 \%$ con ocasión de los comicios de 1999 y al 81\% en los del 2005. Estos factores institucionales y políticos nos han llevado a calificar la nueva democracia como semisoberana (Huneeus, 2012) por las limitaciones que existieron a la autoridad del congreso y el presidente.

\section{Los apoyos a la democracia}

Uno de los indicadores del desarrollo político, que mostrarían una mayor calidad de la democracia, sería el amplio apoyo que la población entregaría a ésta, especialmente por el buen desempeño económico, con un 7\% de crecimiento promedio anual hasta 1997. Esta mejor situación debiera haber tenido efectos favorables en la formación de la cultura cívica, que se forma en los primeros años, cuando los individuos tienen experiencia con las instituciones y la práctica de ella (Rustow, 1987). Seymour Lipset (1959) había argumentado que existiría una relación positiva entre el crecimiento económico y los apoyos a la democracia, pues aquel daría los bienes materiales que permitirían satisfacer las principales necesidades de los ciudadanos, que son económicas. Esta percepción podría ser más visible porque el régimen militar tuvo una grave crisis económica en 1983, que perjudicó a la inmensa mayoría de la población, incluso de los estratos medios, que les llevó a protestar contra el gobierno.

Sin embargo, el caso de Chile desmiente esa asociación. En vez de producirse un aumento de los apoyos a la democracia desde su inauguración en 1990 y en un contexto de crecimiento sostenido, ésta se mantuvo estable. En comparación a los países de América Latina que tienen una larga tradición democrática, como Uruguay y Costa Rica, de acuerdo a los resultados del Latinobarómetro, los apoyos

9 Seguimos a Dalton y Wattemberg (2000) y Schmitter (1999) sobre las funciones de los partidos. 
son considerablemente inferiores, pues en estos fueron 75\% y $72 \%$ respectivamente según el Latinobarómetro 2010. El apoyo a la democracia en Chile es levemente superior a la media regional, $63 \%$ y $61 \%$ respectivamente. ${ }^{10}$

Para medir los apoyos a la democracia se emplea una pregunta formulada por Juan Linz a fines de los años '70 y es la siguiente: “¿Con cuál de las siguientes frases está Ud. más de acuerdo? La democracia es preferible a cualquier otra forma de gobierno; en algunas circunstancias un gobierno autoritario puede ser preferible a uno democrático y a la gente como yo nos da los mismo un régimen democrático que uno no democrático". Quienes optan por la primera alternativa serían partidarios de la democracia; los que escogen la segunda, prefieren el autoritarismo y los que prefieren la tercera alternativa, son indiferentes a la forma de gobierno ${ }^{11}$.

La pregunta ha sido aplicada por el CERC regularmente desde 1986, siendo una serie de tiempo con más de 22 mediciones, que permite sacar conclusiones más sólidas que si se dispone de algunas encuestas, realizadas en algunas etapas del desarrollo de la democratización, especialmente en su etapa inicial, como ha ocurrido con el caso de España (por ejemplo McDonough, Barnes y López Pina, 1986; Morlino y Montero, 1995; Montero, Gunther y Torcal, 1998; Torcal, 2009). Es una base de datos, única en Chile, pues esta pregunta no ha sido aplicada por las otras encuestas que se hacen con regularidad desde los años 90, con excepción del Latinobarómetro, que la aplicó por primera vez en $1995 .^{12}$

Hay una considerable volatilidad en los apoyos a la democracia, antes y después de su inauguración, con apoyos que no superan el 66\%, que puede ser considerado como moderado, en el contexto de las favorables resultados económicos, con tres excepciones en que fue superior, y algunas encuestas en que el apoyo fue menor, llegando el 48\% en septiembre de 2000 y varias encuestas en que el apoyo estuvo entre $53 \%$ y el $58 \%$. Cuando cae el apoyo a la democracia, se produce un aumento especialmente de los indiferentes a la forma de gobierno, como en la de octubre de 2005, cuando se empinaron al 29\%. Los partidarios del autoritarismo son una minoría, con sólo dos encuestas en que superó el 20\% de los encuestados.

10 Según los resultados del Latinobarómetro, www.latinobarometro.org.

11 La pregunta es aplicada por los principales estudios de cultura cívica comparados, desde el Eurobarómetro, el Latinobarómetro, el Afrobarómetro y el Estudio Mundial de Valores.

12 La encuesta que realiza el Centro de Estudios Públicos (CEP), de carácter bianual y regularmente desde 1987, no incluye esta pregunta. 
Esta volatilidad también se manifiesta en las encuestas realizadas antes de la inauguración de la democracia, cuyos resultados dan cuenta de las expectativas sobre ésta. En la primera, realizada en junio de 1986, a una muestra del gran Santiago, un 61\% dio apoyo a la democracia, que bajó levemente al 58\% en la siguiente, en noviembre de 1987, usando una muestra nacional, representativa del 98\% de la población. El apoyo subió en las dos encuestas siguientes, llegando al 74\% en la encuesta de noviembre de 1988, es decir, inmediatamente después del plebiscito del 5 de octubre, cuando el triunfo del No creó un clima muy favorable a la democracia, había una fecha para el término del régimen militar, pues se debían realizar elecciones presidenciales y parlamentarias en un año y luego ocurriría la transferencia de poder al mandatario elegido. El apoyo se desplomó en las mediciones siguientes, hasta el $58 \%$ en la encuesta de abril de 1989, para subir en las siguientes, alcanzando un $76 \%$ en la de abril de 1990, inmediatamente después de la inauguración de la democracia el 11 de marzo de ese año. Los dos altos apoyos se pueden explicar por haber reflejado un clima de opinión en un particular contexto político, sin la competencia entre los partidarios del régimen militar y su oposición o entre los partidos, de gobierno y de oposición.

\section{Gráfico 2}

Apoyo a la Democracia, 1986-2013

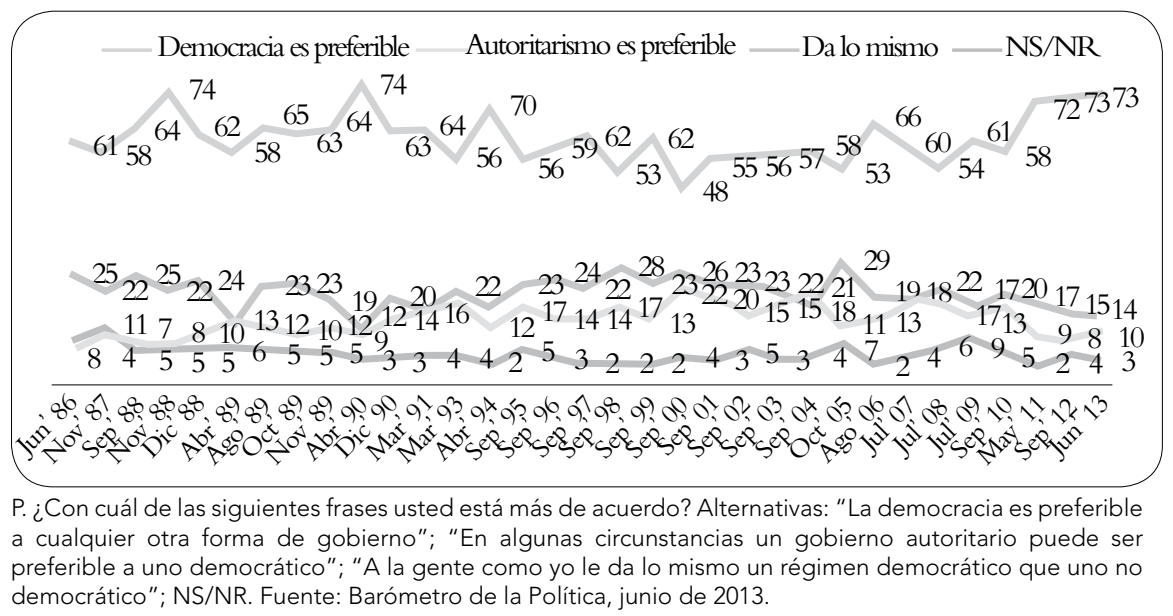

En la tercera oportunidad en que el apoyo sobresalió sobre las tendencias anteriores, llegando al 70\%, fue en abril 1994, un mes después que asumiera el segundo gobierno democrático del presidente Eduardo Frei Ruiz-Tagle (1994-2000), electo 
con el 56\% de los votos. El resultado mostró un aumento significativo respecto de la encuesta de marzo de 1993, cuando había sido 56\%. El contexto era similar al de las dos encuestas que tuvieron apoyos similares.

La volatilidad en los apoyos a la democracia se terminó luego de la alternancia de gobierno de 2010, porque en las tres últimas mediciones se ha mantenido constante y muy alto, lo que se explica por incremento que se da entre los partidos de derecha desde que son parte del gobierno, lo que confirma la presencia de factores políticos que influyen en estos resultados. Los votantes de la UDI y RN dan un menor apoyo a la democracia que los del PDC, PPD y PS, (Cuadro 1).

\section{Cuadro 1}

Apoyo a la democracia, 1995- 2013, por intención de voto.

\begin{tabular}{|c|c|c|c|c|c|c|c|c|c|c|c|c|c|c|c|c|c|c|c|}
\hline & $\begin{array}{c}\text { Sep } \\
1995\end{array}$ & Sep & Sep & Sep & Sep & Sep & Sep & Sep & Sep & Sep & Oct & Ago & Jul & Jul & Jul & Sep & May & Oct \\
2998 & 1999 & 2000 & 2001 & 2002 & 2003 & Jun \\
2004 & 2005 & 2006 & 2007 & 2008 & 2009 & 2010 & 2011 & 2012 & 2013 \\
\hline UDI & 30 & 36 & 37 & 25 & 41 & 22 & 31 & 46 & 39 & 25 & 46 & 42 & 44 & 25 & 23 & 46 & 71 & 66 & 61 \\
\hline RN & 35 & 34 & 36 & 42 & 37 & 29 & 37 & 51 & 40 & 30 & 45 & 53 & 42 & 37 & 50 & 49 & 71 & 72 & 68 \\
\hline PDC & 71 & 74 & 75 & 65 & 75 & 67 & 79 & 74 & 76 & 77 & 77 & 80 & 73 & 77 & 80 & 61 & 83 & 78 & 81 \\
\hline PPD & 68 & 83 & 76 & 75 & 82 & 79 & 84 & 72 & 70 & 89 & 78 & 82 & 73 & 86 & 94 & 75 & 83 & 93 & 92 \\
\hline PS & 70 & 77 & 83 & 64 & 82 & 74 & 81 & 81 & 80 & 87 & 77 & 74 & 79 & 86 & 96 & 84 & 84 & 83 & 89 \\
\hline Otros & 49 & 62 & 63 & 58 & 53 & 46 & 64 & 47 & 65 & 80 & 49 & 69 & 80 & 45 & 65 & 91 & 69 & 75 & 78 \\
\hline Total & 56 & 59 & 62 & 53 & 62 & 48 & 57 & 56 & 58 & 58 & 53 & 66 & 60 & 54 & 61 & 58 & 72 & 73 & 76 \\
\hline
\end{tabular}

Sólo alternativa "La democracia es preferible a cualquier otra forma de gobierno". Fuente: Barómetro de la Política, junio de 2013.

También se debiera reflejar el crecimiento económico en las respuestas a la satisfacción con la democracia. Sin embargo, los resultados muestran que es baja, con excepción de la encuesta realizada en 1990, en que el 75\% de los encuestados declararon estar muy o bastante satisfechos. Sin embargo, este resultado se desplomó rápidamente, pues en la encuesta de 1991 la satisfacción cayó al 60\%, para seguir bajando en forma constante en las siguientes mediciones, y llegar al 36\% en la de 1998. Este último resultado se puede explicar por el impacto de la crisis económica, existiendo un 45\% "poco satisfecho" y un 14\% "nada satisfecho". ${ }^{13}$ En 2009, un porcentaje similar, 42\%, se declaró "satisfecho" -suma de "muy" y "bastante satisfecho"-, cuando todavía se

13 Las preguntas sobre la situación económica personal y del país mostraron que la crisis asiática produjo un fuerte impacto en los resultados, cayendo ambos indicadores. 
sentían los efectos de la crisis del sistema financiero internacional, que golpeó la economía chilena especialmente el 2008 (Cuadro 2).

\section{Cuadro 2}

Satisfacción con la democracia, 1990-2013, por intención de voto. Suma de respuestas "Muy y bastante satisfecho".

\begin{tabular}{|c|c|c|c|c|c|c|c|c|c|c|c|c|c|c|c|c|c|c|c|c|c|c|c|c|}
\hline & $\begin{array}{l}\mathrm{Ag} \\
90\end{array}$ & $\begin{array}{c}\text { Mar } \\
91\end{array}$ & $\begin{array}{c}\text { Mar } \\
92\end{array}$ & $\begin{array}{c}\text { Mar } \\
93\end{array}$ & $\begin{array}{c}\text { Sep } \\
95\end{array}$ & $\begin{array}{c}\text { Sep } \\
96\end{array}$ & $\begin{array}{c}\text { Sep } \\
97\end{array}$ & $\begin{array}{c}\text { Sep } \\
98\end{array}$ & $\begin{array}{c}\text { Sep } \\
99\end{array}$ & $\begin{array}{c}\text { Sep } \\
00\end{array}$ & $\begin{array}{c}\text { Sep } \\
01\end{array}$ & $\begin{array}{c}\text { Sep } \\
02\end{array}$ & $\begin{array}{c}\text { Sep } \\
03\end{array}$ & $\begin{array}{c}\text { Sep } \\
04\end{array}$ & $\begin{array}{c}\text { Ago } \\
05\end{array}$ & $\begin{array}{c}\text { Dic } \\
06\end{array}$ & $\begin{array}{c}\text { Dic } \\
07\end{array}$ & $\begin{array}{l}\mathrm{Jul} \\
08\end{array}$ & $\begin{array}{c}\text { Dic } \\
08 \\
\star \star \star\end{array}$ & $\begin{array}{l}\text { Jul } \\
09\end{array}$ & $\begin{array}{c}\text { Sep } \\
10\end{array}$ & $\begin{array}{c}\text { May } \\
11\end{array}$ & $\begin{array}{l}\text { Oct } \\
12\end{array}$ & $\begin{array}{c}\text { Jun } \\
13\end{array}$ \\
\hline UDI & 48 & 23 & 23 & 27 & 18 & 25 & 28 & 26 & 14 & 13 & 12 & 25 & 27 & 12 & 11 & 21 & 28 & 14 & 40 & 15 & 48 & 63 & 45 & 54 \\
\hline $\mathrm{RN}$ & 58 & 37 & 22 & 39 & 39 & 22 & 26 & 24 & 14 & 15 & 9 & 23 & 21 & 22 & 25 & 35 & 27 & 15 & 48 & 23 & 56 & 61 & 65 & 54 \\
\hline PDC & 87 & 77 & 52 & 57 & 52 & 60 & 65 & 56 & 46 & 59 & 59 & 50 & 55 & 56 & 65 & 67 & 51 & 44 & 62 & 57 & 56 & 48 & 42 & 35 \\
\hline PPD & $\star \star$ & $\star \star$ & 44 & $\star \star$ & 38 & 46 & 52 & 40 & 47 & 65 & 55 & 54 & 45 & 57 & 66 & 64 & 57 & 57 & 67 & 88 & 71 & 42 & 49 & 25 \\
\hline PS & 84 & 68 & 40 & 49 & 36 & 37 & 42 & 33 & 36 & 61 & 46 & 64 & 62 & 71 & 67 & 61 & 64 & 47 & 80 & 67 & 66 & 35 & 42 & 31 \\
\hline Total & 75 & 60 & 37 & 44 & 35 & 39 & 44 & 36 & 29 & 38 & 29 & 35 & 36 & 35 & 45 & 44 & 38 & 29 & 51 & 42 & 60 & 43 & 40 & 34 \\
\hline
\end{tabular}

P. Tomando todo en cuenta, ¿cuán satisfecho está Ud. con la democracia aquí en Chile? ¿Diría Ud. que está muy satisfecho, bastante satisfecho, poco satisfecho o nada satisfecho?

La pregunta en esa ocasión era: "Está Ud. conforme con la manera en que funciona la democracia en Chile?" y se consideró "Muy conforme y conforme"; ${ }^{\star \star}$ El porcentaje del PPD está incluido en el del PS.

***Se sumaron "muy" y "algo satisfecho. Fuente: Barómetro de la Política, junio de 2013

Las respuestas al apoyo a la democracia y de satisfacción están influidas por las preferencias políticas de los entrevistados, pues son mayoritarias en ambas preguntas en los votantes de los partidos de la coalición de gobierno y son minoritarios en los de la oposición (Huneeus y Maldonado 2003).

Dos preguntas adicionales permiten profundizar en la relación que existiría entre el crecimiento económico y los apoyos a la democracia. La primera se refiere a su legitimidad, definida por Juan J. Linz como el convencimiento que tienen los ciudadanos de que es el mejor sistema político para el país, más allá de que, en la realidad, tiene defectos. Esta pregunta, en rigor, no evalúa el contexto político y económico, sino que da cuenta de la adhesión a la democracia, independientemente de cuál es su capacidad para satisfacer las necesidades de la población. Esto se mide a través de la segunda pregunta, que se refiere a la eficacia de la democracia, definida como "la capacidad de un régimen político de encontrar soluciones a sus principales problemas” (Linz 1978), en los cuales sobresalen los económicos. Ambos atributos de la democracia, legitimidad y eficacia, no son estáticos, sino cambiantes, por lo que las autoridades electas por el pueblo deben esforzarse por lograr que la ciudadanía los reconozca. Quienes ven una relación positiva entre el crecimiento y el desarrollo 
político esperarían el fortalecimiento de la eficacia de la democracia. Se podría esperar una volatilidad en las respuestas a la legitimidad, como ha ocurrido con las preguntas sobre los apoyos y la satisfacción con la democracia.

Para conocer la percepción de la legitimidad de la democracia, Linz formuló la frase "la democracia es el mejor sistema político para un país como el nuestro". Los que están de acuerdo con ella reconocerían legitimidad a la democracia. Los resultados muestran un acuerdo ampliamente mayoritario y estable, incluso en las dos mediciones hechas antes de 1990, $84 \%$ y $85 \%$ respectivamente, que confirman el clima subjetivo favorable hacia el cambio de régimen. En la tercera oportunidad en que se aplicó esta pregunta, en marzo de 1991, el resultado fue levemente superior, $87 \%$, para bajar al 78\% en marzo de 1993 y volver a subir en abril de 1994, inmediatamente después de que Frei Ruiz-Tagle asumiera como presidente. En las mediciones posteriores, hubo un alto porcentaje de acuerdo con esta frase, que confirma una disposición favorable a la democracia considerada como "el mejor sistema político". Las encuestas en que el acuerdo fue inferior al 70\% fueron excepcionales, llegando al 68\% y al 65\%, a comienzos del gobierno de Lagos, sin que se haya producido antes, en el contexto de la crisis económica asiática. Mejoró al 71\% en 2001 y se mantuvo constante, siendo especialmente alto en la encuesta del 2006, cuando comenzaba el gobierno de Michelle Bachelet, la primera mujer en América del Sur que llega a la presidencia a través de elecciones. El apoyo a la legitimidad de la democracia en 2009 fue 66\%, el más bajo que ha habido en los 20 años en que se ha aplicado esta pregunta en 22 oportunidades y la economía del país había salido de la crisis financiera internacional, que explica la disminución que se produjo en la encuesta realizada en 2008. 
Gráfico 2

Satisfacción con la democracia, legitimidad y eficacia, 1989-2013

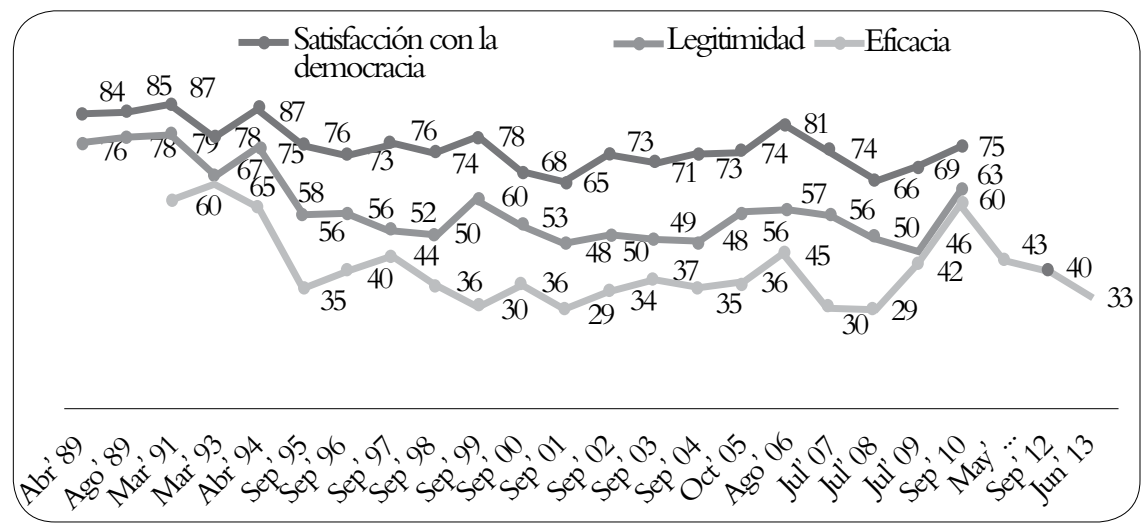

P: *Legitimidad: Acuerdo a la frase: "La democracia es el mejor sistema político para un país como el nuestro". "Eficacia: Acuerdo a la frase: La democracia permite que se solucionen los problemas que tenemos los chilenos. Satisfacción: Respuestas "muy" y "bastante satisfechos con la democracia". Fuente: Barómetro de la Política, CERC, 1989 - 2013.

La eficacia es medida, siguiendo a Linz, mediante el acuerdo con la afirmación "La democracia permite que se solucionen los problemas que tenemos todos los chilenos”. Se podría esperar un alto grado de aprobación a esta frase, a la luz de los excelentes indicadores de desempeño económico y social. Sin embargo, los resultados no lo confirman, predominando una evaluación crítica de ésta. La percepción a favor de la eficacia fue alta sólo en las encuestas hechas antes e inmediatamente después de la inauguración de la democracia en 1990, llegando al 84\% en la de agosto de 1990, para después caer el $67 \%$ y seguir bajando, situándose en porcentajes algo superiores al 50\%, siendo aun inferiores en las mediciones de 2001, 2003 y 2004 (Gráfico 2).

\section{La doble ruptura de 1973}

Para analizar por qué el crecimiento económico no se ha traducido en un mayor apoyo a la democracia, sino que persiste una baja satisfacción con ésta y una baja percepción de eficacia, se deben examinar no sólo las limitaciones de los partidos y otras instituciones políticas, que actuarían como filtro, deteniendo los efectos positivos de aquella, sino examinar los rasgos del crecimiento y el estilo empleado por la autoridad económica. Los estudios sobre la democratización han descuidado este análisis (Morlino 2010), ${ }^{14}$ probablemente porque éstos tienen

14 Una excepción es Przeworski (1991). 
presente las democracias avanzadas, que llegaron al desarrollo antes y, en el caso de España, éste se alcanzó antes de la inauguración de la democracia en 1977. Este examen es necesario porque la política económica fue fundamental en el primer gobierno democrático de las nuevas democracias de América Latina, sin que Chile fuera una excepción a ello, aunque enfrentaba una situación distinta a los demás países: el sistema económico estaba en mejores condiciones y ya había sufrido una profunda transformación de acuerdo a orientaciones neoliberales que tenían considerable impacto en el proceso político, pues las principales reformas ya se habían implementado en dictadura, con un costo económico y social muy elevado (Ffrench-Davis, 2008). Ello marca una diferencia sustantiva con otros casos de la región, en donde estas reformas se implementaron bajo regímenes democráticos.

El golpe militar del 11 de septiembre de 1973 provocó violentamente una doble ruptura en el desarrollo político del país. Por un lado, interrumpió la larga tradición democrática, con alternancia de gobiernos en elecciones competitivas y estado de derecho, poniendo fin al gobierno de la Unidad Popular del presidente Salvador Allende (PS) (1970-1973), e instauró un régimen autoritario del general Augusto Pinochet (1973-1990). El bombardeo e incendio del palacio de La Moneda, con la muerte del presidente Allende, mostró a los chilenos -y también al mundola magnitud de la voluntad rupturista de los nuevos gobernantes ${ }^{15}$. Con relativa celeridad, se estableció un nuevo orden político que llegaría a ser un Estado dual, caracterizado por la alta coerción, también aplicada cuando estaba consolidado, provocando profundas heridas que permanecen en la sociedad, y el rostro amigable representado por la transformación económica de orientación neoliberal, dirigida por "los Chicago Boys". ${ }^{16}$

Por otro lado, provocó una ruptura con el sistema económico existente, con alcances tan profundos como la anterior, porque fue en dos direcciones. Los nuevos gobernantes cancelaron de inmediato las reformas estructurales impulsadas desde el gobierno del presidente Eduardo Frei Montalva (PDC) (1964-1970), ${ }^{17}$ como la reforma agraria y la sindicalización campesina, y la nacionalización de las empresas realizada por el gobierno de la Unidad Popular (con la excepción de la Gran Minería del Cobre, nacionalizada en 1971), habiendo creado una amplia "área de propiedad

\footnotetext{
15 Fue una toma del poder muy distinta a otros golpes de Estado en América Latina en esos años, como en el Perú en 1968, cuando en la madrugada los militares sacaron del palacio de gobierno al presidente Fernando Belaúnde Terry y lo enviaron al exilio fueran del país.

16 Un análisis del régimen de Pinochet se encuentra en Huneeus (2000; 2007).

17 Un interesante libro sobre este gobierno es el de Molina (1971).
} 
social" en que se encontraban las principales firmas, como también muchas medianas y pequeñas. En segundo lugar, luego de algún tiempo, radicalizaron su voluntad rupturista, pues desmantelaron el Estado de bienestar establecido desde comienzos del siglo XX, constituido por elementos como un sistema de pensiones basado en un esquema de reparto, salud y educación públicas, y el rol empresarial del Estado (construido desde los años 40 por iniciativa del Estado a través de la CORFO) en los principales sectores de la economía, desde la energía y la siderurgia, hasta las telecomunicaciones, el transporte, entre otras actividades. Ambos desarrollos institucionales -Estado de bienestar y empresario- estaban identificados con el desarrollo del Estado chileno ${ }^{18}$.

Los políticos e intelectuales civiles, que serían los asesores más influyentes de los militares, aprovecharon la oportunidad que abría el comienzo de un nuevo régimen para proponer metas más ambiciosas a los uniformados, que dieran una perspectiva histórica más relevante que resolver la crisis económica y política producida por el gobierno de la Unidad Popular, argumentando que había que cambiar las raíces de los problemas. El desarrollo político y económico de Chile habría sido una "decadencia" desde fines del siglo XIX, cuando se habría producido la ruptura del “consenso" religioso y seguida luego por la ruptura del consenso social y político. El golpe de Estado en 1973 no era más que la culminación de esa decadencia (Vial 1984). Era necesario refundar la república y eligieron la figura de Diego Portales para simbolizar esta voluntad. ${ }^{19}$

Esta ruptura del sistema económico no fue neutral políticamente, pues tuvo objetivos políticos. Además de buscar superar la crisis económica de 1973 y dar prosperidad a los chilenos, se planteó establecer un nuevo sistema económico apoyado en otras bases del Estado y la sociedad, que llevaran a demoler las bases sociales de los partidos históricos de centro y de izquierda y permitir que los grupos civiles que apoyaban al régimen militar fueran dominantes cuando se restableciera la competencia electoral. La transformación económica reforzaría la ruptura política, que se tradujo en un nuevo orden político, la democracia protegida y autoritaria, consagrada en la

18 La educación pública tenía una larga historia, pues fue reconocida en la Constitución de 1833, que estableció que "la educación es atención preferente del Estado" y la salud pública fue impulsada especialmente en el siglo XX por iniciativas de médicos de distintos partidos, destacando los conservadores Exequiel González Cortés y Eduardo Cruz-Coke.

19 Portales tuvo un papel importante en el establecimiento de la "república autoritaria" de comienzos de la república independiente.Véase Collier y Sater (1996). 
Constitución de 1980, para asegurar la continuidad del nuevo orden económico después que los militares regresaran a sus cuarteles.

\section{La doble ruptura de 1973 y sus efectos en 1990}

La doble ruptura de 1973 fue parcialmente enfrentada cuando se restableció la democracia en 1990. Se recuperó la tradición de presidentes elegidos en elecciones competitivas y con partidos políticos, pero hubo continuidad de importantes instituciones del régimen anterior, impuestas por éste, que limitaron la profundidad del cambio de régimen. Entre éstas destaca la Constitución de 1980, la continuidad del ex dictador como comandante en jefe del Ejército durante ocho años, después de los cuales podía entrar al Senado en su calidad de ex presidente, los nueve senadores designados, que impidieron a la Concertación tener mayoría en el Senado, el sistema binominal y "las supramayorías" para aprobar tanto la reforma a la carta fundamental como una amplia variedad de temas que eran materia de ley, que daban a la minoría un poder de veto para frenar las reformas que propusiera el gobierno.

La permanencia de Pinochet, un hecho inédito en las nuevas democracias, tuvo enormes repercusiones en el proceso político, porque tenía un enorme poder, basado no sólo en los recursos constitucionales, sino también en el apoyo que tenía en la oposición, la élite empresarial y una parte del país, que lo admiraban por haber "salvado al país del comunismo" y ser responsable del "milagro económico". Pinochet no se limitó a su función institucional, actuando al interior de su institución, para impulsar la reinserción profesional del Ejército y ayudar a la consolidación de la democracia, sino que actuó en la arena política, para impedir que el presidente Aylwin llevara adelante la política de verdad y justicia por las violaciones a los derechos humanos y defendió el régimen que presidió durante casi diesiciete años.

Esta labor opositora del general Pinochet fue reforzada porque contó con el apoyo de los parlamentarios de oposición, que lo habían acompañado en su gobierno. En la cámara alta, con excepción de Sebastián Piñera (RN), todos los senadores de los dos partidos de oposición, la UDI y RN, elegidos en 1989, habían participado en posiciones de poder o asesoría en el régimen que encabezó. Hasta las elecciones del 2005, siete de los ocho senadores de la UDI electos habían participado en alguna posición de autoridad en su gobierno y diez de los catorce senadores de RN.

La presencia del general Pinochet en la arena política tuvo múltiples consecuencias en el proceso político, pues fortaleció la decisión de la UDI y RN de mantener el orden institucional, rechazando las reformas propuestas por el gobierno; éste usó 
este hecho para disciplinar a las organizaciones sindicales y sociales, cuyos dirigentes asumieron esa conducta, que tendría altos costos, y tuvo un considerable efecto en la opinión pública, pues sus acciones y declaraciones mantuvieron vigente la memoria del régimen que encabezó, con visiones divididas sobre él y sobre las violaciones a los derechos humanos. La evaluación crítica de la democracia que arrojan los datos de encuestas tienen un doble fundamento: los partidarios de la UDI y RN la cuestionan porque siguen valorando al régimen anterior y los de la Concertación consideran que no se alcanzaron las promesas que se hicieron antes de $1990 \mathrm{y}$ critican la actitud de las autoridades de gobierno ante el ex dictador. ${ }^{20}$

Estas limitaciones fueron impuestas por el contexto institucional, definido a partir del tipo de transición que tuvo Chile, con un régimen militar que no cayó como consecuencia de una guerra, como en Argentina, que desmanteló el poder castrense y su apoyo en la población, o terminó en medio del fracaso de la gestión de los militares, como en Perú o Uruguay, que desprestigió a los militares, sino que terminó según la regulación sucesoria establecida en la carta fundamental, a partir del plebiscito de 1988, en el cual el general Pinochet obtuvo un importante apoyo electoral, 43\% de los votos. Además, los partidos que le apoyaron en el plebiscito, la UDI y RN defendieron la permanencia del ex dictador en la dirección del Ejército, cuando fue criticado por el presidente Aylwin por sus declaraciones o acciones y justificaron la continuidad de las normas institucionales establecidas en la Constitución de 1980. Sin embargo, no todo se puede explicar por los factores institucionales heredados; también había espacio decisorio para tener distintas actitudes hacia el sistema económico.

\section{La decisión de no enfrentar la ruptura económica}

La decisión de no enfrentar la ruptura del sistema económico, optando más por su continuidad que por la reforma, no fue impuesta por el contexto institucional, por los enclaves autoritarios, sino que fue una decisión voluntaria, según la apreciación de las condiciones políticas que hizo el conglomerado.

20 Esto lo reconoce Diamond, al sorprenderse por la contradicción existente entre los buenos indicadores macroeconómicos y el bajo apoyo a la democracia, expresando que esto último "no es algo que esperaba de un país tan próspero económicamente y con una muy larga tradición democrática. Las dudas sobre la democracia en Chile parecen estar referidas al continuado "reserva de poder' que tienen los militares y la falta de responsabilidad por los crímenes cometidos en el pasado" (Diamond 1999: 48). 
Enfrentar el sistema económico no significaba volver atrás, hacia un sistema económico de planificación centralizada o restituir el latifundio en el campo. No se trataba de provocar una ruptura, sino una reforma del sistema económico, a partir de interpelar sus debilidades y limitaciones, que dañaban su dinamismo y perjudicaban el desarrollo político. Se consideró a los empresarios como una élite homogénea, a la cual había que enfrentar con cuidado, buscando atender sus intereses para superar las desconfianzas por la crisis de 1973, sin tomar en cuenta que era un sector con diferencias, habiendo menor desconfianza en los ejecutivos de las empresas extranjeras radicadas en Chile, como lo habían demostrado Barrell y Payne (1995) en sus entrevistas realizadas en 1987.

La decisión del equipo económico contrasta con la actitud del presidente Aylwin de enfrentar las violaciones a los derechos humanos cometidos por el régimen militar, constituyendo la Comisión Rettig a los pocos días de jurar como presidente, llamando a buscar la verdad y a hacer justicia "en la medida de lo posible" porque estaba la ley de amnistía y otros obstáculos institucionales y personales en el poder judicial. No vaciló ante la oposición del general Pinochet y desoyó los temores de algunos de sus más cercanos colaboradores en el sentido que ello podría llevar a un enfrentamiento con los militares. Las dificiles condiciones políticas de la transición aconsejaban una estrategia opuesta: extrema prudencia en la política de derechos humanos e imaginación y audacia en la política económica, marcando diferencias con el modelo económico neoliberal, que tuviera correspondencia con el discurso crítico de la oposición a la dictadura y la orientación de centro izquierda del gobierno.

La opción por la continuidad implicó abdicar de las críticas formuladas antes por los economistas y políticos de la Concertación, quebuscaban identidad y separación del programa de "los Chicago Boys". Ello perjudicaría a los partidos en la competencia electoral. Había opciones de "modelo" alternativo, como la economía social de mercado, difundido en Chile por la Fundación Konrad Adenauer, que trabajó desde los años 60 con el PDC. El programa de "crecimiento con equidad" del gobierno Aylwin redujo su identidad a las políticas sociales para reducir la pobreza.

La decisión de no enfrentar la ruptura económica producida desde 1973 tuvo una enorme influencia en el desarrollo de la democratización, pues la estrategia de consolidación de la democracia se definió en torno a la gestión económica. Aunque la política hacia los militares y al general Pinochet era clave en el corto plazo, se estimó que, a mediano y largo plazo, el futuro de la democracia se jugaba en el buen desempeño económico, que proporcionaría los bienes materiales que permitirían 
satisfacer las urgentes demandas de la mayoría de la población, con cinco millones de pobres, y, con ello, lograr el apoyo a la democracia y al gobierno.

Edgardo Boeninger (1997) argumenta que en 1990 hubo un consenso en el sentido de dar la continuidad al sistema económico establecido y buscar su consolidación, sin cuestionar sus rasgos neoliberales y plantear cambios: "Entre los economistas de la Concertación había clara conciencia acerca de la necesidad de consolidar el proceso de crecimiento en curso desde 1985, aunque al mismo tiempo formulaban severas críticas al modelo neoliberal desde la perspectiva de la justicia social" (Boeninger 1997, p. 384). Esta afirmación se aleja de la realidad, porque entre los economistas del PDC había partidarios de reformar el sistema económico y también en la izquierda, alternativas que fueron ignoradas. ${ }^{21}$

Se partió de la base que el crecimiento económico sería favorable a la consolidación de la democracia, siguiendo la antigua tesis de Lipset (1959) que había destacado la relación positiva que existiría entre la expansión económica y el desarrollo político. Sin embargo, no se consideró que esa relación podía ser más compleja, pues los factores políticos podían influir en la evaluación subjetiva del proceso económico por parte de los ciudadanos, especialmente el escenario institucional. Si bien se podrían alcanzar muy buenos resultados económicos, ello no sería apreciado por la población porque la evaluación subjetiva estaría filtrada por las opiniones políticas.

Esta decisión, seguida por el segundo gobierno democrático de Eduardo Frei RuizTagle (1994-2000), del mismo partido de Aylwin, pudo haber sido revisada por el presidente Ricardo Lagos (2000-2006), el primer mandatario socialista desde Salvador Allende, pues podría atribuirse a que fue influida por las posiciones centristas del PDC, partido de los anteriores mandatarios y de los respectivos ministros de Hacienda. Sin embargo, Lagos no interpeló la modernización económica del autoritarismo y, más aún, la acentuaría, cuando impulsó un conjunto de iniciativas

21 El PS criticó las Bases programáticas de la Concertación en un extenso documento dirigido al presidente del PDC, Andrés Zaldívar, firmado por el secretario general del partido, Jorge Arrate, el encargado de la Secretaría de Estudios y programas del PS, Gonzalo Martner, y el encargado de la Comisión Económica del partido, Carlos Ominami. El documento fue filtrado y entregado a la prensa algunos días antes de las elecciones de diciembre de 1989 por Pablo Barahona, jefe de la campaña presidencial de la derecha, y lo reprodujo El Mercurio “Texto del memorándum sobre el pacto secreto entregado por Barahona", 4 de diciembre de 1989. La controversia pública provocada llevó a Arrate a desconocer la existencia del documento para impedir el escalamiento de un conflicto con el PDC, El Mercurio, 5 de diciembre de 1989, “J. Arrate niega existencia de carta con discrepancias" y luego calificaría de "burdo montaje" la acusación de Barahona, El Mercurio, 9 de diciembre de 1989. 
económicas en estrecha cooperación con las organizaciones empresariales, como lo fue "la Agenda Pro Crecimiento".

Esta orientación del gobierno de Lagos fue acentuada por Michelle Bachelet, cuyo ministro de Hacienda, un economista independiente, profesor de la Universidad de Harvard, tenía una orientación económica más conservadora que sus antecesores. La contradicción entre gobiernos de centro-izquierda y políticas económicas de centro derecha tuvo consecuencias negativas en el electorado y activistas de los partidos de la Concertación, especialmente en la izquierda.

Los buenos resultados conseguidos con relativa rapidez en términos de crecimiento, empleo, caída de la inflación, mejoramiento de las remuneraciones y otros resultados macroeconómicos tuvieron un efecto path dependence (Pierson, 2000) en la estrategia de legitimación por el desempeño económico, pues generaron fuertes incentivos para sostener que ese camino debía ser mantenido por parte de los gobiernos posteriores, en el convencimiento de que, de esa manera, se seguirían obteniendo esos buenos resultados. Esa estrategia no fue revisada para enfrentar sus debilidades o carencias, ni para hacer frente a nuevos desafios o problemas cuando el crecimiento cayó con motivo de la crisis asiática que golpeó fuertemente a la economía chilena en 1998, produciendo efectos que se prolongaron varios años.

\section{La visión tecnócrata del equipo económico}

La estrategia económica del primer gobierno democrático, seguida por los siguientes, tuvo dos rasgos que ayudan a explicar que no se hayan producido los bienes políticos esperados por el equipo económico de Aylwin. En primer lugar, enfatizó una práctica de consenso con los empresarios y la oposición, incluso cuando la democracia estaba consolidada, para aprobar las principales políticas, pero los acuerdos fueron en torno a las instituciones y políticas heredadas, sin buscar convencerlos de apoyar reformas al sistema económico que mejoraran su calidad. Esta actitud no tuvo una reacción favorable de los empresarios que hubiera matizado su compromiso político con el régimen anterior y los partidos de derecha, manteniendo una defensa muy rígida de las instituciones y políticas neoliberales.

Esto llevaría a una práctica de colusión sobre las principales materias económicas, como el tema tributario y las reformas laborales, que fueron sacadas del debate público. Esto redujo la agenda de la competencia política, lo cual afectó la competencia electoral y la acción de los partidos, que no pudieron perfilarse en temas centrales de su identidad programática e histórica. La competencia, como afirma Bartolini (1999, 2000), implica 
no sólo la existencia de varios candidatos disputando un escaño o la presidencia, sino también que los votantes perciban las diferencias entre ellos, para que puedan tomar una decisión fundada racionalmente y no en consideraciones personales.

En segundo lugar, el equipo económico no se guió por consideraciones políticas, evaluando sus decisiones de acuerdo a sus consecuencias en la distribución de poder y en el electorado, sino por consideraciones técnicas, aplicando una lógica de expertos, con el convencimiento que la ciencia económica les proporcionaba las alternativas correctas. Esta actitud correspondía más bien a la lógica tecnocrática que O’Donnell (1995) criticó en los equipos económicos de los regímenes autoritarios o gobiernos democráticos aplicando políticas neoliberales, que piensan que "los economistas saben mejor" que los profesionales de otras disciplinas. La lógica tecnocrática era contraria a la lógica política, de negociaciones y compromisos entre distintos intereses, con el esfuerzo de convencer a los partidos y parlamentarios para que apoyen sus decisiones.

Fue una manera distinta de tomar decisiones no sólo en sus fundamentos, sino también en el estilo, todos mirando el proceso político desde arriba, sin considerar los intereses de los votantes y sin tampoco considerar las opiniones de los partidos y los parlamentarios. Importantes decisiones del ministerio de Hacienda, desde la reforma tributaria de 1990, hasta el financiamiento compartido en la educación de 1993 se tomaron sin considerar a las bancadas de la Concertación y, en el segundo caso, sin discutir esta iniciativa con las autoridades del ministerio de Educación.

El discurso económico penetró en el sistema político, influyendo en las campañas electorales, pues el votante fue considerado más como un consumidor que como un ciudadano, asumiéndolo como carente de lealtades partidistas y memoria histórica, dando por sentado que podría ser convencido a través del marketing. Con esas ideas, no se justificaba cuidar las lealtades de los votantes de los partidos de la Concertación porque en el mercado electoral había plena competencia. Los partidos se vieron afectados por la valoración de la privatización de la economía a través de la subcontratación de sus principales tareas en consultoras o empresas, dejando en un segundo plano el trabajo de activistas y las organizaciones partidistas. Además, el énfasis en el consenso impidió a los partidos desarrollar sus identidades, especialmente programáticas, que interesan a sus activistas y ayudan a mantener la adhesión de sus votantes. Si antes de 1973 los partidos tuvieron un enorme poder sobre las autoridades elegidas por el pueblo, desde 1990 este espacio fue ocupado 
por los expertos. ${ }^{22}$ No se buscó la modernización de la política sino su privatización, y la política fue subordinada a la economía. El debilitamiento de los partidos se explica no sólo por responsabilidad de sus dirigentes, que no se preocuparon de su modernización, sino también por este contexto desde la dirección económica.

\section{Costos de la continuidad del sistema económico: concentración de la riqueza}

El crecimiento económico, la joya de la democratización, no ha producido los bienes políticos esperados porque tiene debilidades y carencias. Se apoya principalmente en las exportaciones de materias primas, especialmente cobre, celulosa, productos agrícolas y otros, que tienen altos costos medioambientales, una baja capacidad de generar empleo, siendo éste precario y de bajos salarios. Estos rasgos de la estructura económica impactan en el sistema privado de pensiones, porque no se dan las condiciones para que la capitalización individual permita acumular un ahorro suficiente para entregar una pensión digna. Sólo el 65\% de los trabajadores dependientes cotiza en AFP, el $58 \%$ de estos cotizantes tiene una remuneración mensual menor a $\$ 500.000$ (mil dólares) y, peor aún, la densidad de cotización, es decir, el porcentaje del tiempo que la persona efectivamente cotiza, es muy baja, un $52 \%$ como promedio, que implica que la cantidad de ahorro que acumula para su jubilación es apenas la mitad de su remuneración. ${ }^{23}$

Una segunda e importante debilidad es la desigualdad en la distribución de los ingresos y la alta concentración de la riqueza. Las desigualdades de ingreso no disminuyeron en forma significativa durante las administraciones de la Concertación, pues el coeficiente Gini, a comienzos de los años $90^{24}$, fue 0,55 y avanzó hacia el año 2006 al 0,54. Uruguay, con una trayectoria democrática tan prolongada como la de Chile y con una izquierda tan poderosa como en éste, mantuvo en el mismo período un coeficiente Gini considerablemente menor, 0,44 a comienzos de los 90 y 0,45 en la etapa posterior. Argentina, en el mismo período, vio aumentada las desigualdades de ingreso, pues de un coeficiente Gini de 0,44 subió a uno de 0,50.

\footnotetext{
22 Silva $(1992 ; 2010)$ tiene razón cuando destaca la continuidad del poder de los tecnócratas en el régimen de Pinochet, en el cual sobresalen "los Chicago Boys", y en la democracia, en que destacan los economistas de CIEPLAN, porque ello fortaleció el peso del argumento de los expertos sobre el de los políticos.

23 Datos de junio de 2013.

24 Estos datos los hemos tomado de Huber y Stephens (2012, tabla 5.2).
} 
Un examen más preciso de las desigualdades de los ingresos es a través de la información del Servicio de Impuestos Internos (SII), pues la de encuestas no da cuenta de ello, ya que los ricos los subestiman. El análisis de la información del SII por López, Figueroa y Gutiérrez (2013) les llevó a concluir que la desigualdad de los ingresos es mayor y el coeficiente Gini efectivo sería "seis puntos porcentuales más alto que el que reportan estimaciones existentes usualmente utilizadas, con lo que la distribución del ingreso del país resulta ser mucho más concentrada que lo que habitualmente se señala".

La información del SII, además, mide la concentración de la riqueza, lo que no es posible hacer a través de las encuestas. El estudio de López, Figueroa y Gutiérrez (2013) concluyó que existe una altísima concentración de ella, superior a la que existe en los demás países de la Organización para la Cooperación y el Desarrollo Económico (OCDE). El 1\% más rico de los chilenos concentra el 30,5\% del ingreso, mientras que EE.UU., el país que le sigue, es del 21\%. Esta concentración es aún mayor, pues el $0,1 \%$ concentra el $17,6 \%$ del ingreso, un porcentaje muy superior al que existe en los EE.UU., en el cual alcanza el 10,5\%. Aún más, si se examina la riqueza que tiene un porcentaje menor, el 0,01\%, que son 1.200 individuos, ellos reúnen el 10,1\% de la riqueza, que representa el doble de la que se concentra en los EE.UU. por ese mismo porcentaje de individuos. La concentración de la riqueza en Chile es mayor que en los 21 países que disponen de una información comparable.

Las desigualdades de ingresos no son irrelevantes para el proceso político, pues pueden contradecir principios fundamentales de la democracia, como "un hombre, un voto", "la igualdad ante la ley" (Bartels, 2008), impidiendo que se den condiciones necesarias para que haya igualdad política, uno de los requisitos procedimentales de la democracia, porque "los ciudadanos deben tener alguna medida de igualdad en ingreso, riqueza y status" (Diamond y Morlino, 2005). Las importantes consecuencias de las desigualdades en la democracia fueron resumidas por Robert A. Dahl cuando se preguntó: “en un sistema político en el que casi cada adulto puede votar, pero en el que el conocimiento, la riqueza, la posición social, el acceso a la administración y otros recursos están desigualmente distribuidos, ¿quién gobierna realmente?" (Dahl 1961). Dahl examinó este problema en la ciudad de New Haven, en la cual la concentración de la riqueza era menor a la de Chile, pues el $0,1 \%$ de sus habitantes tenía el 3,2\% del ingreso total, pues es $17,6 \%$, la quinta parte. Dahl matizó el impacto de la concentración de la riqueza en el funcionamiento de la democracia, porque los "notables económicos" eran uno de los varios actores que participaban en las decisiones públicas, habiendo instituciones que hacían posible un 
gobierno democrático -los partidos, los grupos de interés, la administración pública dirigida por personal profesional, la prensa libre, las asociaciones voluntarias y otras-.

La concentración de la riqueza constituye una limitación a la calidad de la democracia porque esas organizaciones en Chile tienen un grado de precariedad que no hace posible impedir que el poder económico pueda influir en forma decisiva en las decisiones del sistema político. Además, porque no hay mecanismos institucionales que aseguren la autonomía de las decisiones del gobierno y el congreso, pues no hay financiamiento público de los partidos, que deben recurrir a las contribuciones de empresas y de particulares para llevar adelante su labor, lo cual restringe su autonomía. Tampoco existe una ley de lobby para limitar la influencia de los grupos de presión y las empresas en las decisiones del gobierno y el Congreso. Estas condiciones se ven acentuadas por "la puerta giratoria" de ex ministros y altos funcionarios que gestionan ante el gobierno y el congreso proyectos privados, acentuando la tendencia hacia la privatización de la política y no hacia su modernización y la de los partidos. Este escenario institucional hace "muy dificil impedir que la riqueza económica no sea aprovechada para convertirla en poder político. Los ricos pueden usar sus recursos para financiar a políticos y a partidos que están de acuerdo con ellos, o disuadir a aquellos que discrepan para que cambien su posición” (Crouch 2011).

La discrepancia entre los buenos indicadores objetivos y una evaluación subjetiva crítica se confirma en la pregunta sobre quienes se benefician del desarrollo económico, habiendo una amplísima mayoría que responde que son los ricos y no los pobres, ni los chilenos en general, ni el propio entrevistado. Estas cuatro preguntas guardan una correspondencia muy potente, avanzando en la misma dirección, pues muestran un tipo de crecimiento que beneficia a una minoría, confirmando la percepción sobre el fortalecimiento de las desigualdades. A pesar del enorme esfuerzo hecho por los gobiernos de la Concertación para disminuir la pobreza y poner énfasis en difundir esta política, sólo una minoría, 28\%, opina que los pobres se han beneficiado del crecimiento que ha tenido el país, contradiciendo la realidad objetiva constituida por la reducción de la pobreza como consecuencia de políticas sociales (Gráfico 3). También una minoría de los chilenos dice beneficiarse del crecimiento, evaluación que sólo mejora el 2009 en el contexto de la elección presidencial y dos bonos extraordinarios de $\$ 40.000$ cada uno ( $\$ 80$ cada uno) entregados para enfrentar la crisis del sistema financiero, reactivando el consumo. Existe prácticamente unanimidad en que el crecimiento sólo ha beneficiado a los ricos, opinión compartida por un 76\% de los encuestados. 
Gráfico 3

¿Quién se beneficia con el Desarrollo Económico?, 1993-2012

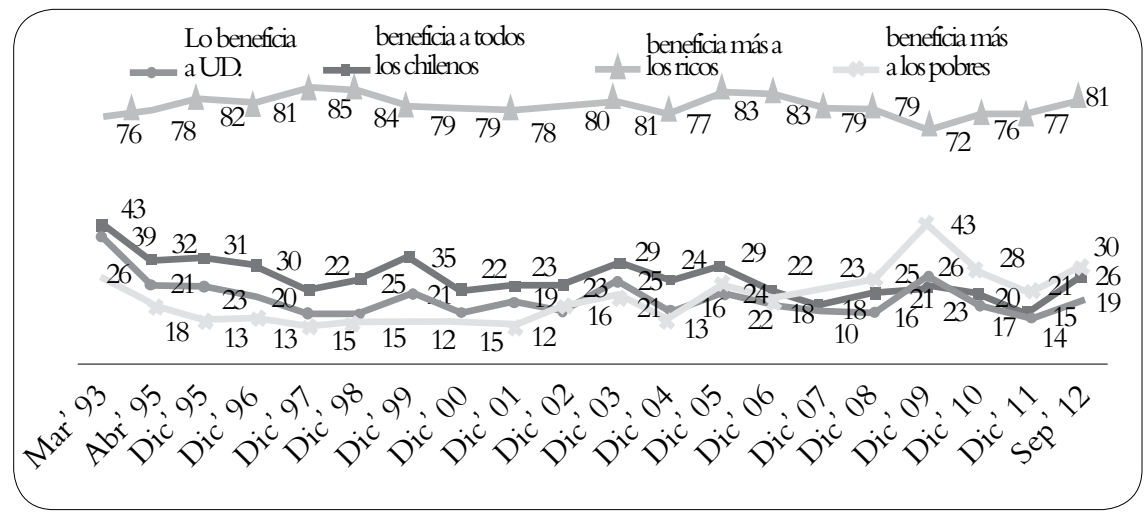

P. El desarrollo económico que está teniendo Chile, ¿a quién cree Ud. que beneficia? (Solo respuestas "sí"). Fuente: Barómetro de la Política CERC, Septiembre de 2012

Por todos estos motivos, el crecimiento económico no produce automáticamente beneficios en el proceso político, como lo planteó Lipset (1959), sino que también puede ser fuente de dificultades que lo limiten y hasta lo perjudiquen.

El crecimiento en sí mismo no es un motivo que provoque adhesión política en los chilenos, porque una minoría se siente beneficiado por éste. Por el contrario, predomina la opinión de que una minoría se ha beneficiado, acentuando con ello la percepción de las desigualdades. Los resultados de Latinobarómetro 2011 ponen a Chile como el país con la peor percepción de la distribución de ingresos, pues sólo un $6 \%$ de la población cree que hay una distribución "muy justa" o "justa”, cuando la media de los 18 países de América Latina considerados en ese estudio es más del triple, $20 \%$. Uruguay y Costa Rica, que tienen una democracia establecida por largas décadas y con una calidad comparable a la de Chile, tienen una opinión pública considerablemente menos crítica, pues $27 \%$ y $24 \%$ considera que hay una muy justa y justa distribución del ingreso.

En consecuencia, las dificultades que enfrentan los partidos y los factores que llevaron al desplome de los de la Concertación el 2009, sin recuperar su fortaleza institucional y su prestigio ante sus adherentes, no se explican sólo por las decisiones de sus dirigentes, que no se esforzaron por modernizarlos, sino también por las condiciones institucionales y el tipo de discurso impuesto por el equipo económico, que impuso el predominio de la economía y descuidó y hasta maltrató la política y a los partidos. Si el crecimiento económico no favoreció el desarrollo político, 
ello debe explicarse no sólo analizando el comportamiento de los partidos y los parlamentarios, sino también es necesario tomar en cuenta el contenido y el estilo de la gestión económica y su desinterés y hasta maltrato de la política.

\section{Conclusiones}

Cuarenta años después del golpe militar y un cuarto de siglo después del plebiscito de 1988, que gatilló el fin del régimen de Pinochet, los resultados de la democratización obligan a ser prudentes y no narcisistas respecto de la evaluación del cambio de régimen, sin haber motivos para concluir que fue "la mejor transición de América Latina".Las heridas causadas en el pasado por el golpe y la represión no han cicatrizado, porque mientras los políticos de centro e izquierda reconocen los errores cometidos antes de 1973, los de derecha, que participaron en el régimen militar y callaron ante los abusos, no tienen similar actitud y justifican, de una u otra forma, la coerción aplicada por el régimen militar. El crecimiento económico favorece a la población, pero adquirió orientaciones que han perjudicado el desarrollo político al optarse por la continuidad del sistema económico establecido por el régimen militar y optar por una visión tecnocrática de la gestión del gobierno, descuidando la política y los partidos. El debilitamiento de los partidos se debe no sólo a decisiones de sus dirigentes, que no los modernizaron, sino también a factores externos, provenientes del estilo de liderazgo y la orientación de la política económica impulsada desde 1990. Los partidos y la política no fueron modernizados, sino más bien privatizados.

El 11 de septiembre de 2013 le dio a Chile una nueva coyuntura histórica con desafios institucionales en el sistema económico y político que no puede seguir esquivando. Parece que es recurrente en nuestra historia la reticencia a enfrentar oportunamente los problemas complejos. Antes ocurrió con el atraso en la agricultura, que fue incapaz de alimentar a los chilenos; hoy son las desigualdades, la concentración de la riqueza y una economía dependiente de la explotación de las materias primas. La historia no se repite, pero ella muestra que enfrentar tardíamente desafios claves del desarrollo económico y político tiene mayores costos que hacerlo oportunamente. La disyuntiva de Chile hoy no es como en 1973, el peligro del regreso de los militares al poder, sino la posibilidad de consolidar una democracia de mediocre calidad y un sistema económico basado en la exportación de materias primas y los servicios, que será incapaz de dar prosperidad a la amplia mayoría y, menos aún, estabilidad social. 


\section{Referencias bibliograficas}

Angell, Alan (2009). "Democratic Governance in Chile". En Mainwaring, Scott y Scully Timothy R. (eds.) Democratic Governance in Latin America. Stanford: Stanford University Press.

Barrell, Ernest y Payne, Leigh A. (eds.) (1995). Business and Democracy in Latin America. Pittsburgh: University of Pittsburgh Press.

Bartels, Larry M. (2008). Unequal Democracy. The Political Economy of the New Guilded Age. Nueva York: Russell Sage Foundation -Princeton: Princeton University Press.

Bartolini, Stefano (1999). "Collusion, competition, and Democracy Part I". Journal of Theoretical Politics, Vol. 11, N4, pp. 435-470.

Bartolini, Stefano (2000). "Collusion, competition, and Democracy Part II", Journal of Theoretical Politics,Vol. 12, N¹, pp. 33-65.

Bascuñán, Carlos; Correa, Germán; Maldonado, Jorge y Sánchez,Vicente (eds.) (2009). Más acá de los sueños, más allá de lo posible. La Concertación en Chile. Santiago: LOM Ediciones, Corporación Justicia y Democracia y Fundación Clodomiro Almeyda.

Boeninger, Edgardo (1997). “Democracia en Chile. Lecciones para la gobernabilidad” Santiago: Editorial Andrés Bello.

Collier, Simon y Sater, William F. A. (1996). History of Chile, 1808-1994. Cambridge: Cambridge University Press.

Collins, Cath (2010). Post-Transitional Justice. Human Rights Trials in Chile and El Salvador. University Park:The Penssylvania State University Press.

Crouch, Colin (2011). The Strange Non-Death of Neoliberalism. Cambridge: Polity Press.

Dahl, Robert A. (1961) Who governs? Democracy and Power in an American City. New Haven: Yale University Press.

Dalton, Russel J. y Wattenberg, Martin P. (eds.) (2000). Parties without Partisans. Oxford: Oxford University Press.

Diamond, Larry (1999). "Developing Democracy. Toward Consolidation". Baltimore: The John Hopkins University Press.

Diamond, Larry y Morlino, Leonardo (eds) (2005). "Assessing the Quality of Democracy”. Baltimore:The Johns Hopkins University Press.

Drake, Paul y Jaksic, Iván (eds) (1995). The Struggle for Democracy in Chile. Londres: University of Nebraska Press. 
Ensignia, Jaime y Nolte, Detlef (eds.) (1991). Modelfall Chile? Ein Jahr nach dem demokratischen Neuanfang. Hamburgo: Institut für Iberoamerika-Kunde.

Ffrench-Davis, Ricardo (2008). Entre el neoliberalismo y el crecimiento con equidad. Tres décadas de política económica en Chile. Santiago: J.C. Sáez Editor.

Ffrench-Davis, Ricardo (2013). "Avances y retrocesos del desarrollo económico de Chile en los gobiernos de la Concertación por la Democracia”. En Rodrigo Contreras (ed.) Le Chili post-Pinochet. 20 ans de gouvernements de la Concertation de Partis pour la Démocratie. Paris, L'Harmattan. (por aparecer)

Garretón, Manuel Antonio (1989). La posibilidad democrática en Chile. Santiago: Flacso.

Garretón, Manuel Antonio (1995). Hacia una nueva era política. Estudio sobre las democratizaciones. Santiago: Fondo de Cultura Económica.

Gerchunoff, Pablo y Llach, Lucas (1998). El ciclo de la ilusión y el desencanto. Un siglo de políticas económicas argentinas. Buenos Aires: Ariel.

Hall, Peter A. (1986). Governing the Economy: The Politics of State Intervention in Britain and France (Europe and the International Order). Oxford: Oxford University Press.

Huber, Evelyne, y John D. Stephens (2012). Democracy and the Left. Social Policy and Inequality in Latin America. Chicago:The University of Chicago Press.

Huneeus, Alexandra (2010). "Judging from a Guilty Conscience: The Chilean Judiciary's Human Rights Turn”. Law \& Social Inquiry,Vol. 35, N¹, pp. 99-135.

Huneeus, Carlos (1985). La Unión de Centro Democrático y la transición a la democracia en España. Madrid: Centro de Investigaciones Sociológicas - Siglo XXI Editores.

Huneeus, Carlos (2000). El régimen de Pinochet. Santiago: Editorial Sudamericana.

Huneeus, Carlos (2007). The Pinochet Regime. Boulder, Col.: Lynne Rienner.

Huneeus, Carlos (2012a). "Presidencialismo semisoberano". Revista Uruguaya de Ciencia Política,Vol. 21, N², pp. 31-54.

Huneeus, Carlos (2012b) "La derrota de la Concertación en las elecciones del 2009 y la alternancia de gobierno en Chile". En Ludolfio Paramio (ed.) Clases medias y procesos electorales en América Latina. Madrid: Catarata.

Huneeus, Carlos y Maldonado, Luis (2003). “Demócratas y nostálgicos del antiguo régimen. Los apoyos a la democracia en Chile”. Revista Española de Investigaciones Sociológicas, $\mathrm{N}^{\circ} 103$, pp. 9-49.

Huntington, Samuel (1991). The Third Wave. Democratization in the Late Twentieth Century. Londres: University of Oklahoma Press. 
Katzenstein, Peter J. (1987). Policy and Politics in West Germany. The Growth of a Semisovereing State Filadelfia:Temple University Press.

Keynes, John Maynard (1936). The General Theory of Employment, Interest and Money. Londres: Macmillan.

Linz, Juan J. (1978). Crisis, Breakdown, and Reequilibration. Baltimore: Johns Hopkins University Press.

Lipset, Seymour Martin (1959). "Some Social Requisites of Democracy: Economic Development and Political Legitimacy". American Political Science Review, Vol. LIII: 1, pp. 69-105.

López, Ramón; Figueroa, Eugenio; Gutiérrez C., Pablo (2013). "La 'parte del león': Nuevas estimaciones de la participación de los súper ricos en el ingreso de Chile”, Serie Documentos de Trabajo, Facultad de Economía y Negocios, Universidad de Chile.

Manfred G. Schmidt, (2002). "Germany: the grand coalition state". En: Colomer, Josep M. (ed.) Political Institutions in Europe. Londres: Routledge, 2a edición.

McDonough, Peter; Barnes, Samuel H. y López Pina, Antonio (1986). "The Growth of Democratic Legitimacy in Spain”. American Political Science Review, vol.80, N³. pp. $735-760$.

Molina, Sergio (1971). El proceso de cambio. Santiago: Editorial Universitaria.

Morlino, Leonardo y Montero, José Ramón (1995). "Legitimacy and Democracy in Southern Europe", en: Richard Gunther, P.Nikiforos Diamandouros y Hans-Jürgen Puhle (eds). The Politics of Democratic Consolidation. Southern Europe in Comparative Perspective. Baltimore:The Johns Hopkins University Press.

Muñoz, Oscar (2007). El modelo económico de la Concertación 1990-2005. ¿Reformas o cambio? Santiago: FLACSO Chile-Catalonia.

Montero, José Ramón, Richard Gunther y Mariano Torcal (1998). "Actitudes hacia la democracia en España: Legitimidad, descontento y desafección”. Revista Española de Investigaciones Sociológicas, N83, pp. 9-49.

Morlino, Leonardo (2010). Introducción a la investigación comparada. Madrid: Alianza Editorial.

Niclauss, Karlheinz (1974). Demokratiegründung in Wetsdeutschland. Die Enstehung der Bundesrepublik von 1945-1949. München: Piper.

O’Donnell, Guillermo (1995). “Do Economists know best?”. Journal of Democracy, Vol. 6, $\mathrm{N}^{\circ} 1$, pp. 23-28. 
Pierson, Paul (2000). "Increasing Returns, Path Dependence, and the Study of Politics". American Political Science Review,Vol.94, N², pp. 251-267.

Pinto, Aníbal (1958). Chile, un caso de desarrollo frustrado. Santiago: Editorial Universitaria.

Przeworski,Adam (1991). Democracy and the Market. Cambridge: Cambridge University Press.

Przeworski, Adam (2011). A la sombra de las dictaduras. La democracia en América Latina. Buenos Aires: Fondo de Cultura Económica.

Rouquié, Alan (1984). El Estado militar en América Latina. Buenos Aires: Emecé Editores.

Rouquié, Alain (2011). A la sombra de las dictaduras. La democracia en América Latina. Buenos Aires: Fondo de Cultura Económica.

Rustow, Dankward (1987). "Transición a la democracia. Elementos para un modelo dinámico”. En Carlos Huneeus (compilador). Para vivir la democracia. Santiago: CERC - Editorial Andante.

Sartori, Giovanni (1980). Partidos y sistemas de partidos. Madrid: Alianza Editorial.

Silva, Patricio (2010). En nombre de la razón. Tecnócratas y Política en Chile. Santiago: Ediciones Universidad Diego Portales.

Schmitter, Phillippe (1999). "Critical Reflections of the "Functions" of Political Parties and their Performance in Neo-Democracies". En Wolfgang Merkel y Andreas Busch (eds.) Demokratie in Ost und West, Frankfurt a.M.:, Suhrkamp.

Silva, Patricio (1992). "Technocrats and politics in Chile: from the Chicago Boys to the CIEPLAN Monks”. Journal of Latin American Studies, vol. 23, N². pp. 385-410.

Silva, Patricio (1998). In the Name of reason. Technocrats and Politics in Chile. University Park:The Pennsylvania State University Press.

Torcal, Mariano; Montero, José Ramón y Gunther, Richard (2003). “Ciudadanos y partidos en el sur de Europa. Los sentimientos antipartidos". Revista Española de Investigaciones Sociológicas, N¹01, pp. 9-48. 101/0.

Torcal, Mariano (2009). "Los orígenes del apoyo democrático en la España postfranquista", en Nigel Towson (ed.). España en cambio: el Segundo franquismo, 1959-1975. Madrid: Siglo XXI.

Vial, Gonzalo. (1984) "Decadencia, Consensos y Unidad Nacional en 1973”, Dimensión Histórica de Chile Nr. 1, pp. 140-164. 